\title{
Planejamentos pedagógicos voltados para crianças com deficiência intelectual: experiências colaborativas a partir da ação do Atendimento Educacional Especializado
}

Pedagogical planning for children with intellectual disability: collaborative experiences from the action of Specialized Educational Service

Planes pedagógicos para niños con discapacidad intelectual: experiencias colaborativas desde la acción del Servicio Educativo Especializado

Jáima Pinheiro de Oliveira

Professora pós-doutora da Universidade Federal de Minas Gerais, Belo Horizonte, MG, Brasil

E-mail: jaima.ufmg@gmail.com ORCID: https://orcid.org/0000-0002-0156-3804

Maria Almerinda de Souza Matos

Professora pós-doutora da Universidade Federal do Amazonas, Manaus, AM, Barsil

E-mail: ufamneppd@gmail.com ORCID: https://orcid.org/0000-0002-4776-2155

Recebido em 07 de agosto de 2021

Aprovado em 20 de outubro de 2021

Publicado em 27 de dezembro de 2021

\section{RESUMO}

Esse artigo abordou a temática de planejamentos pedagógicos para crianças com deficiência intelectual, numa perspectiva de articulação entre o Atendimento Educacional Especializado (AEE) e a sala comum. $O$ objetivo do estudo foi mapear as produções científicas que pudessem fornecer indicadores para auxiliar nesses planejamentos pedagógicos com perspectiva colaborativa. Tratou-se de uma revisão sistemática, com critérios e estratégias de busca que levaram em consideração a qualidade de uma revisão de literatura a partir da Assessing the Methodological Quality of Systematic Reviews (AMSTAR). Os resultados indicaram 459 trabalhos considerando os termos mais relevantes vinculados à prática pedagógica no Tesauros Brasileiro de Educação, quais sejam: formação de professores, recursos de ensino e currículo. Após aplicação dos filtros, foram analisados na íntegra 74 estudos, cujos principais indicadores foram: atividades pedagógicas individualizadas e diferenciadas com utilização de adaptações curriculares; formação de professores com ênfase para uma assunção da pessoa com deficiência como sujeito que aprende; mediação do conhecimento e ênfase em colaboração entre os professores de apoio e da sala comum; práticas pedagógicas que consideram características e maneiras diferentes de acesso ao conhecimento. Concluímos que os estudos problematizam questões vinculadas ao campo da didática, porém, alguns ainda desconsideram aspectos da ação docente desenvolvida com e para essas crianças, priorizando elementos que promovem a participação delas em atividades da sala comum.

Palavras-chave: Deficiência Intelectual; Práticas Pedagógicas; Atendimento Educacional Especializado. 
http://dx.doi.org/10.5902/1984686X67106

\section{ABSTRACT}

This article addressed the theme of pedagogical planning for children with intellectual disabilities, in a perspective of articulation between the Specialized Educational Service (AEE) and the common classroom. The objective of the study was to map the scientific productions that could provide indicators to assist in these pedagogical planning with a collaborative perspective. It was a systematic review, with search criteria and strategies that considered account the quality of a literature review based on the Assessing the Methodological Quality of Systematic Reviews (AMSTAR). The results indicated 459 works considering the most relevant terms linked to pedagogical practice in the Brazilian Thesaurus of Education: teacher training, teaching resources and curriculum. After applying the filters, 74 studies were fully analysed, whose main indicators were: individualized and differentiated pedagogical activities using curricular adaptations; teacher training with emphasis on the assumption of the person with a disability as a learner; mediation of knowledge and emphasis on collaboration between support and common classroom teachers; pedagogical practices that consider different characteristics and ways of accessing knowledge. We conclude that the studies problematize issues related to the field of didactics, however, some still disregard aspects of the teaching action developed with and for these children, prioritizing elements that promote their participation in activities in the common classroom.

Keywords: Intellectual Disability; Pedagogical practices; Specialized Educational Service.

\section{RESUMEN}

Este artículo abordó el tema de la planificación pedagógica para niños con discapacidad intelectual, en una perspectiva de articulación entre el Servicio Educativo Especializado (AEE) y el aula común. El objetivo del estudio fue mapear las producciones científicas que pudieran proporcionar indicadores para ayudar en esta planificación pedagógica con una perspectiva colaborativa. Se trató de una revisión sistemática, con criterios y estrategias de búsqueda que tuvo en cuenta la calidad de una revisión bibliográfica basada en la Evaluación de la Calidad Metodológica de las Revisiones Sistemáticas (AMSTAR). Los resultados indicaron 459 trabajos considerando los términos más relevantes vinculados a la práctica pedagógica en el Tesauro de Educación Brasileño: formación docente, recursos didácticos y currículo. Después de aplicar los filtros, se analizaron en su totalidad 74 estudios, cuyos principales indicadores fueron: actividades pedagógicas individualizadas y diferenciadas mediante adaptaciones curriculares; formación del profesorado con énfasis en la asunción de la persona con discapacidad como aprendiz; mediación del conocimiento y énfasis en la colaboración entre profesores de apoyo y de aula común; Prácticas pedagógicas que consideran diferentes características y formas de acceso al conocimiento. Concluimos que los estudios problematizan temas relacionados con el campo de la didáctica, sin embargo, algunos aún desconocen aspectos de la acción docente desarrollada con y para estos niños, priorizando elementos que promuevan su participación en actividades en el aula común.

Palabras clave: Discapacidad intelectual; Planificación pedagógica; Servicio Educativo Especializado. 
http://dx.doi.org/10.5902/1984686X67106

\section{Introdução}

As especificidades que permeiam os sujeitos com diagnóstico de deficiência intelectual continuam sendo um desafio, especialmente no ambiente escolar e, por isso, o uso de apoios interdisciplinares ao longo do processo de escolarização desses sujeitos, mais do que nunca, é inquestionável. Este artigo aborda a temática de planejamentos pedagógicos no contexto de articulação ou de colaboração entre o Atendimento Educacional Especializado (AEE) e a sala comum, com foco para crianças com deficiência intelectual.

Inicialmente faremos uma breve menção às concepções de deficiência intelectual que circulam na literatura especializada, problematizando as implicações dessas concepções para a prática pedagógica, de modo geral.

Trata-se de uma revisão sistemática de literatura que enfatizará aspectos dessa prática voltada para estudantes com esse diagnóstico, cuja incidência nas escolas permanece alta. As discussões também abordarão a necessidade de atenção especializada e suportes, uma vez que as manifestações implicam diretamente o processo de escolarização, tais como aquelas relacionadas às alterações comunicativas, interacionais e de adaptação social.

Desse modo, a nossa revisão de literatura pretende responder aos seguintes questionamentos: como têm sido caracterizados os planejamentos pedagógicos e/ou ações pedagógicas voltadas para contextos escolares com a presença de crianças com diagnóstico de deficiência intelectual? Quais as implicações desses planejamentos para uma perspectiva colaborativa nesse trabalho escolar? Quais as implicações desses resultados para futuros estudos com essa temática?

De modo geral, inferimos que o texto traz uma análise diferenciada em relação às demais revisões efetuadas até o momento, na medida que conseguiu avançar em relação aos critérios e estratégias de busca e, também, apontar indicadores e implicações para futuros estudos, de maneira objetiva.

\section{Concepções sobre Deficiência Intelectual}

Não tem como falar sobre as concepções de deficiência intelectual sem nos remeter aos aspectos históricos da educação das pessoas com deficiência em nosso país. No entanto, essa menção será breve, com o intuito de que esse contexto não seja esquecido diante dessa temática. As ideias adotadas aqui sobre isso estão de acordo com o que nos apontou Januzzi (2006). 
http://dx.doi.org/10.5902/1984686X67106

De modo geral, o histórico de escolarização das pessoas com deficiência em nosso país não apresenta diferenças tão marcantes em relação ao processo de atenção à Educação. Inicialmente, apenas classes sociais dominantes tinham acesso a ela e, na medida que essas pessoas começaram a precisar de mão de obra técnica e de votos, passaram a ver uma necessidade de se ampliar esse acesso. Porém, a escassez de vagas nas escolas indicou, por conseguinte, a necessidade de processos seletivos que culminaram em diagnósticos de normalidade e anormalidade para justificar o não acesso à escola para algumas camadas populares. De maneira resumida, esses processos funcionavam como mecanismo de seleção social e deram origem a muitos casos de deficiência e de debilidade mental, expressão bastante utilizada à época (JANUZZI, 2006).

Esse processo não mudou muito ao longo dos anos, Patto (2015), por exemplo, indicou uma maneira diferente de pensar sobre o fracasso escolar, retirando a culpa por esse fracasso apenas do sujeito e problematizando aspectos do contexto sociocultural no qual ele está inserido e, portanto, atribuindo a esse fenômeno outras responsabilidades relacionadas às desigualdades sociais. Por meio de uma análise minuciosa realizada pela autora, ela aponta conclusões importantes como as que se seguem: as teorias sobre 0 fracasso escolar que enfatizam o déficit e as diferenças culturais precisam ser revistas; o fracasso escolar da escola pública está relacionado às características do próprio sistema que produz obstáculos ao alcance de seus objetivos; e alguns discursos científicos podem naturalizar esse processo.

Essa análise contribuiu e ainda contribui muito para pensar sobre as dificuldades de aprendizagem ainda muito presentes na escola e com concepções que demandam uma análise que tenha o objetivo de promover a acessibilidade atitudinal diante desses sujeitos (OLIVEIRA et al, 2012).

Em relação à concepção médica, podemos dizer que ela avançou um pouco, já que, embora persistam as classificações, elas não estão mais atreladas ao Quociente de Inteligência (QI), mas sim aos níveis e tipos de suportes que precisam ser fornecidos às pessoas que recebem esse diagnóstico médico. Essa ideia ampara-se em documentos legais como os da Associação Americana de Psiquiatria (APA, 2014), em que a Deficiência Intelectual é caracterizada como um estado multidimensional particular de funcionamento desde a infância e influenciado diretamente pelos apoios recebidos. Apoios estes, definidos enquanto conjunto de estratégias, recursos e serviços oferecidos com o intuito de promover a participação e adaptação social do sujeito. 
http://dx.doi.org/10.5902/1984686X67106

Essa definição também tem avançado em relação a uma das principais associações dedicadas a essa temática, no que se refere ao diagnóstico, classificação e suportes necessários a essas pessoas, a saber: a American Association on Intellectual and Developmental Disabilities (AAIDD). Desde 2002, na 10ª Edição do Manual da AAIDD, Luckasson et al (2002) já alertavam para que a Deficiência intelectual não fosse considerada como algo inerente à pessoa. Ou seja, não se trata de uma doença ou um transtorno mental, mas sim de uma condição multidimensional afetada positivamente por suportes individualizados e contextualizados. Também nessa época os organizadores desse Manual reiteraram que a avaliação dessas pessoas precisava considerar as diversidades cultural e linguística, assim como as diferenças na comunicação e nos fatores sensoriais, motores e comportamentais (LUCKASSON et al., 2002).

Já na sua 11aㅡ edição, esse Manual (SCHALOCK et al, 2010) avançou ainda mais, destacando as limitações tanto no desenvolvimento intelectual, quanto na conduta adaptativa, expressas em habilidades práticas, sociais e conceituais, com origem antes dos $18^{1}$ anos de idade. Nessa edição foram destacadas as dimensões que devem ser consideradas em relação ao diagnóstico e, principalmente, aos suportes, são elas: a) habilidades de funcionamento intelectual, relacionadas, por exemplo, à capacidade de raciocínio, planejamento e resolução de problemas, pensamento abstrato, reelaboração de novos conceitos a partir do que foi aprendido, dentre outros aspectos; b) Conduta ou comportamento adaptativo, que se refere à experiência social de cada indivíduo e, portanto, está relacionada à participação social e às práticas adquiridas para corresponder às demandas de sua rotina; c) Saúde, em suas dimensões física e mental, considerando especialmente que se trata de um elemento integrado ao funcionamento individual da pessoa com deficiência intelectual; d) Participação social, que diz respeito à interação e à participação desse sujeito na comunidade à qual ele pertence, bem como aos papéis que ele desenvolve nela; e e) Contextos, que descrevem as condições nas quais a pessoa vive, tomando como referência a perspectiva ecológica, que inclui três níveis da vida social: 0 entorno imediato, a comunidade e outros serviços e as influências gerais da sociedade.

Nessa edição também ficou claro que suporte se referia aos recursos e estratégias com vistas à promoção do desenvolvimento, da educação, de interesses e bem-estar pessoal, todos com o propósito de aprimorar o funcionamento individual. Por isso, foram apresentados: 
http://dx.doi.org/10.5902/1984686X67106

[...] quatro níveis de apoio: Intermitente, fornecido conforme a necessidade do sujeito e por períodos curtos de tempo ao longo da vida; Limitado, caracterizado por consistência ao longo do tempo em ambiente específico durante tempo limitado; Amplo, refere-se ao apoio regular em alguns ambientes e não caracterizado por tempo limitado; e, por fim, Permanente, oferecido com alta intensidade, longa duração ou ao longo da vida e, muitas vezes, envolve vários profissionais e diferentes ambientes de atendimento" (ALLES et al, 2019, p. 374).

Desse modo, ainda que seja necessário atestar essa deficiência para receber esses suportes, os indicadores e a forma de avaliar essas pessoas mudaram graças, também, aos avanços em relação à International Classification of Functioning, Disability and Health. Fizemos questão de deixar essa nomenclatura sem a tradução brasileira, por causa das inúmeras discussões que permeiam essa tradução, vinculadas ao termo Disability (VAZ et al, 2019).

É extremamente importante discutir sobre essas concepções relacionadas à deficiência intelectual, porque elas é que indicam as expectativas diante dessas pessoas, seja, em ambiente domiciliar, social ou escolar. E são essas expectativas que estarão presentes nos trabalhos do dia a dia da escola, foco de nossa pesquisa.

Por isso, a partir do progressivo deslocamento da culpabilização única da não aprendizagem da criança com deficiência para um conjunto de outras variáveis, as práticas pedagógicas devem orientar-se na direção de tornar o ensino acessível a esses alunos e, se for o caso, pensar também em uma diferenciação curricular. É papel do professor compreender que a criança com esse diagnóstico pode ter uma condição qualitativamente diferenciada de desenvolvimento, implicando num ritmo específico de aprendizagem (GHIRELLO-PIRES, 2012). Como também faz parte de sua ação pedagógica encontrar as vias de acesso para que o conhecimento chegue a todos os estudantes.

\section{Práticas pedagógicas colaborativas}

Pensamos que para construir um ambiente inclusivo que aumente a potencialidade de aprendizado de alunos com deficiência intelectual ou que fazem parte do público-alvo da Educação Especial, é necessário refletir sobre a prática docente, considerando fundamentalmente: o planejamento de atividades, as variações metodológicas, as habilidades dos estudantes e, também, estilos e tempos de aprendizagem (LUSTOSA; MELO, 2018).

Zabala (1998) define prática pedagógica como um conjunto de interações, procedimentos e variáveis interacionadas nas situações de ensino. Franco (2016) a 
http://dx.doi.org/10.5902/1984686X67106

considera como uma organização intencional que tem o objetivo de atender expectativas educacionais de uma dada comunidade social. Portanto, dentro dessa prática estão incluídos: o processo de planejamento, a sistematização da dinâmica dos processos de aprendizagem e, também, processos que vão além da aprendizagem, tais como como o estilo do professor e as relações sociais dentro do contexto escolar.

Lustosa e Melo (2018) destacam também a influência das concepções e saberes docentes nessa prática pedagógica, na organização de conteúdo, nos critérios de avaliação e interação com os alunos, ressaltando a necessidade de uma formação docente voltada à compreensão e valorização da diversidade humana. Além disso, ressaltam a necessidade de um conhecimento sobre a aprendizagem do aluno com dificuldades e de como gerir e organizar o trabalho pedagógico em uma sala heterogênea, valorizando o ensino colaborativo e tendo sempre em vista a legislação e as barreiras sociais e educacionais inclusivas encontradas em pesquisas cientificas.

Essas concepções vão ao encontro do que Capellini e Zerbato (2019) concebem como ensino colaborativo. As autoras destacam a colaboração como caminho promissor para uma perspectiva inclusiva no ensino, comentando que o trabalho em equipe deve ser compreendido como uma estratégia humana para alcançar um objetivo de uma tarefa complexa, com resultado efetivo. A contribuição é outra palavra utilizada pelas autoras, pois ela exige interação e ajuda mútua. Em relação à tarefa complexa, é necessário pensar nesse trabalho em direção a um objetivo comum, que, em nosso contexto, trata-se da participação do estudante com deficiência intelectual nas atividades da sala comum.

Tardif (2014) também traz importantes colaborações sobre os saberes docentes, destacando quatro: os saberes da formação profissional, os disciplinares, os curriculares e os saberes da experiência. O primeiro seria baseado na ciência e adquirido durante a formação docente, constituindo o conhecimento pedagógico relacionado aos métodos de ensino. O segundo seria concebido nos campos de conhecimento (linguagem, ciência, exatas, humanas, biológicas) produzidos pela humanidade ao longo dos tempos e adquiridos por meio de instituições educacionais. O terceiro estaria ligado à gestão dos saberes disciplinares e o quarto seria adquirido por meio da experiência docente e das relações profissionais vividas ao longo dessas experiências (TARDIF, 2014).

A partir dessas considerações, observamos que a prática pedagógica envolve vários aspectos, sendo a maior parte deles relacionada com a formação do professor, seja ela inicial ou adquirida ao longo do desenvolvimento profissional. Shulman (1986) nos 
http://dx.doi.org/10.5902/1984686X67106

apresenta três esferas de conhecimento no desenvolvimento do professor: o conhecimento da matéria ensinada, o conhecimento pedagógico da matéria e o conhecimento curricular. A partir desses saberes o professor deve ser capaz de transformar o conteúdo pedagógico para que se adapte em diferentes situações, podendo ser reproduzido de diversas maneiras tornando-o compreensível a todos alunos (SEBASTIÁN-HEREDERO, 2020; ALMEIDA; BIAJONE, 2007).

Considerando esse contexto, este estudo propôs uma Revisão Sistemática de Literatura com o objetivo de mapear as produções científicas que possam auxiliar nos planejamentos pedagógicos com perspectiva colaborativa, no contexto de participação de estudantes com deficiência intelectual.

\section{Caminho metodológico}

Para atingir nosso objetivo, lançamos mão de uma Revisão Sistemática de Literatura relacionada ao tema proposto. A busca para essa revisão foi realizada na Biblioteca Nacional Digital de Teses e Dissertações (BDTD) e seguiu critérios específicos para preservar a qualidade da revisão. Sobre isso, tivemos como base o estudo de Medrado et al. (2014) no que diz respeito às etapas para condução desse tipo de revisão, quais sejam: 1) formulação de uma pergunta relevante; 2) busca na literatura por textos relevantes; 3) análise crítica das evidências em relação à validade e aplicabilidade; 4) coleta de dados; 5) análise e apresentação dos dados; 6) interpretação dos dados; e 7) aperfeiçoamento e atualização da revisão.

Tivemos também como parâmetro de qualidade, os catorze itens considerados por Costa et al (2015) da escala denominada Assessing the Methodological Quality of Systematic Reviews (AMSTAR) para atribuir qualidade a uma revisão de literatura: a) clareza na descrição do objetivo; b) composição das estratégias de busca; c) qual a origem das publicações; d) critérios de inclusão e exclusão para dados mencionados; e) seleção de bases de dados; f) mínimo de juízes para a seleção; g) número de artigos incluídos e excluídos em cada etapa; h) mínimo de juízes para extração de dados; i) descrição das características do estudo; j) forma de avaliação dos métodos utilizados; k) descrição completa dos métodos utilizados e incluídos; I) formação das conclusões baseadas na qualidade metodológica; m) viés de publicação considerado; e n) descrição de conflito de interesses.

Sobre a base escolhida, a Biblioteca Nacional Digital de Teses e Dissertações (BDTD) é o repositório oficial de teses e dissertações brasileiras de acesso aberto. Foi desenvolvida 
http://dx.doi.org/10.5902/1984686X67106

e é coordenada pelo Instituto Brasileiro de Informação em Ciência e Tecnologia (IBICT) e trata-se da principal referência de registros de pesquisas desenvolvidas no país, com repositório funcional desde 2002. Esse repositório é extremamente importante para essas buscas, especialmente, antes das teses e dissertações serem disseminadas em periódicos científicos.

Para padronização e organização dessa busca foram utilizados descritores, obtidos junto ao Tesaurus Brasileiro da Educação que, de alguma forma, se aproximavam e dialogavam com as práticas pedagógicas voltadas para contextos escolares com a presença de crianças com diagnóstico de deficiência intelectual. O Tesaurus Brasileiro da Educação é um vocabulário controlado que reúne termos e conceitos, extraídos de documentos analisados no Centro de Informação e Biblioteca em Educação (CIBEC). Nessa base de descritores há uma relação entre eles, que leva em consideração uma estrutura conceitual da área de Educação e de suas subáreas. Estes termos são destinados à indexação e à recuperação de informações e não se trata de dicionário, mas sim de um instrumento que garante aos documentalistas e pesquisadores o processamento e a busca destas informações.

Para confirmar a frequência mais alta de termos relacionados às práticas pedagógicas e formação de professores foram efetuados testes de buscas na BDTD e durante tais testes os termos mais frequentes foram: prática pedagógica (incluindo plural), formação de professores, recursos de ensino e currículo. Esses descritores foram definidos e combinados com o descritor Deficiência Intelectual utilizando o operador Booleano AND, para que fosse obtido um resultado mais específico. Essa foi a principal estratégia de busca definida.

A busca foi efetuada nas duas primeiras semanas do mês de agosto de 2020, com a participação de dois juízes. Para selecionar os estudos, foram considerados dois filtros. No primeiro (F1), foram observados idioma, período e título: o idioma deveria ser apenas português; o período foi o dos últimos doze anos - esse período foi considerado em razão da publicação da Política Nacional de Educação Especial na Perspectiva da Educação Inclusiva (BRASIL, 2008) e, portanto, das implicações dela em relação às implementações de diretrizes para o AEE e ampliação das Salas de Recursos Multifuncionais. Ainda nesse filtro, o título do artigo deveria conter alguma palavra relacionada aos descritores ou ao tema proposto. Todos os resumos dos estudos que satisfizeram esses critérios foram considerados e inseridos num arquivo único em formato Word, contendo esse resumo e a referência completa do trabalho no formato $A B N T$. 
http://dx.doi.org/10.5902/1984686X67106

Num segundo momento, esses resumos foram lidos para passarem por um filtro 2 . Nessa leitura do resumo (F2) foram consideradas: as pesquisas desenvolvidas com crianças, considerando anos iniciais do ensino Fundamental; pesquisas que abordassem de maneira mais objetiva aspectos da prática pedagógica sem especificar disciplinas e de modo que ajudassem a responder as perguntas de pesquisa do nosso estudo.

A análise final deste corpus selecionado foi pautada em seu conteúdo, com base em duas etapas, dentre as três propostas pela autora Bardin (2011), a saber: exploração do material e tratamento dos dados, que inclui apresentações quantitativas e descritivas, inferências e interpretação. Não foi considerada a etapa de pré-análise ou seleção do material com base na autora, porque essa etapa seguiu critérios e parâmetros da própria Revisão Sistemática de Literatura.

$\mathrm{Na}$ etapa de exploração do material foram efetuados recortes nos documentos selecionados, para que fosse possível chegar às unidades de registros, classificando e agregando as informações em temas, que é uma das opções sugeridas pela autora. $O$ exercício para se chegar a estes temas é a codificação dos dados: "[...] A codificação corresponde a uma transformação - efetuada segundo regras precisas - dos dados brutos do texto, transformação esta que, por recorte, agregação ou enumeração, permite atingir uma representação do conteúdo ou de sua expressão; [...] (BARDIN, 2011, 133). Para auxiliar nessa codificação, lançamos mão da mineração de textos (Voyant Tools) que indicou os termos mais frequentes nos resumos dos artigos selecionados.

A partir dessa codificação é que foi possível agregar os artigos em grandes temas, que posteriormente passaram por revisão para se chegar às categorias. Essa categorização seguiu como critérios, aspectos expressivos dos conteúdos principais trabalhados ao longo das pesquisas. Essa análise norteou a explanação e a compreensão das principais discussões apontadas nos estudos, agrupados nas seguintes categorias: Estratégias pedagógicas e recursos de ensino; Mediação pedagógica; Políticas públicas para melhoria da escola regular e da formação de professores; e Currículo.

Os resultados da busca foram apresentados por meio de tabelas, quadros e figuras utilizando estatística descritiva. Após a leitura e análise minuciosas dos textos, foram realizadas uma apresentação e uma discussão a fim de pontuar as principais implicações dos estudos voltadas para as práticas pedagógicas com esse público-alvo, apontando também, caminhos para as novas contribuições científicas nessa área. 


\section{Resultados}

Para responder ao objetivo de mapear as produções científicas que pudessem auxiliar nos planejamentos pedagógicos com perspectiva colaborativa, apresentaremos: a) a frequência de estudos selecionados, por meio de tabelas, nas quais essas frequências são indicadas antes e após a aplicação dos filtros; b) dados sobre a mineração de textos, por meio de um gráfico e duas figuras, com imagens obtidas com ferramenta específica, e que indicam, por sua vez, os vocábulos mais frequentes presentes nos documentos; e c) os indicadores principais presentes nos textos que podem suscitar ou sugerir elementos para planejamentos pedagógicos com perspectiva colaborativa e suas implicações para futuros estudos, por meio de um quadro. Finalmente, é arrolada uma discussão a respeito desses dados.

1. Frequência de estudos encontrados

Tabela 1 - Resultados da busca antes de qualquer filtro

\begin{tabular}{l|c|c}
\hline Descritores e termo booleano utilizado & $\begin{array}{c}\text { Frequência } \\
\text { absoluta }(\mathrm{n})\end{array}$ & $\begin{array}{c}\text { Frequência } \\
\text { relativa }(\%)\end{array}$ \\
\hline Prática pedagógica AND Deficiência Intelectual & 143 & $31,0 \%$ \\
\hline Formação de professores AND Deficiência Intelectual & 126 & $28,0 \%$ \\
\hline Recursos de ensino AND Deficiência Intelectual & 110 & $24,0 \%$ \\
\hline Currículo & 77 & $17,0 \%$ \\
\hline Total & 456 & $100 \%$ \\
\hline
\end{tabular}

Fonte: Elaboração própria (2021).

Tabela 2 - Resultados da busca após filtros adotados

\begin{tabular}{l|c|c}
\hline Descritores e termo booleano utilizado & $\begin{array}{c}\text { Frequência } \\
\text { absoluta (n) }\end{array}$ & $\begin{array}{c}\text { Frequência } \\
\text { relativa (\%) }\end{array}$ \\
\hline Prática pedagógica AND Deficiência Intelectual & 28 & $38,0 \%$ \\
\hline Formação de professores AND Deficiência Intelectual & 18 & $24,0 \%$ \\
\hline Recursos de ensino AND Deficiência Intelectual & 16 & $22,0 \%$ \\
\hline Currículo & 12 & 16,0 \\
\hline Total & 74 & $100 \%$ \\
\hline
\end{tabular}

Fonte: Elaboração própria (2021).

Foram encontradas 456 teses e dissertações, dentre as quais 74 foram consideradas para análise na íntegra, após aplicação dos filtros e critérios. Muito embora estejamos diante de um tema muito explorado no campo da Educação Especial, com esses descritores, consideramos que a busca retornou uma frequência baixa de pesquisas, principalmente, levando em consideração a repetição de estudos (quase metade) nessas buscas. Isso ocorre, porque normalmente esses estudos utilizam descritores semelhantes. 
http://dx.doi.org/10.5902/1984686X67106

A seguir, apresentaremos duas nuvens de palavras e um gráfico, todos relacionados à mineração dos textos dos resumos dos trabalhos selecionados para análise integral.

2. Mineração de textos a partir do conteúdo da Tabela 2

a) Imagens geradas por meio da mineração de textos dos resumos dos trabalhos selecionados para análise integral

Figura 1 - Palavras mais frequentes no corpus textual analisado

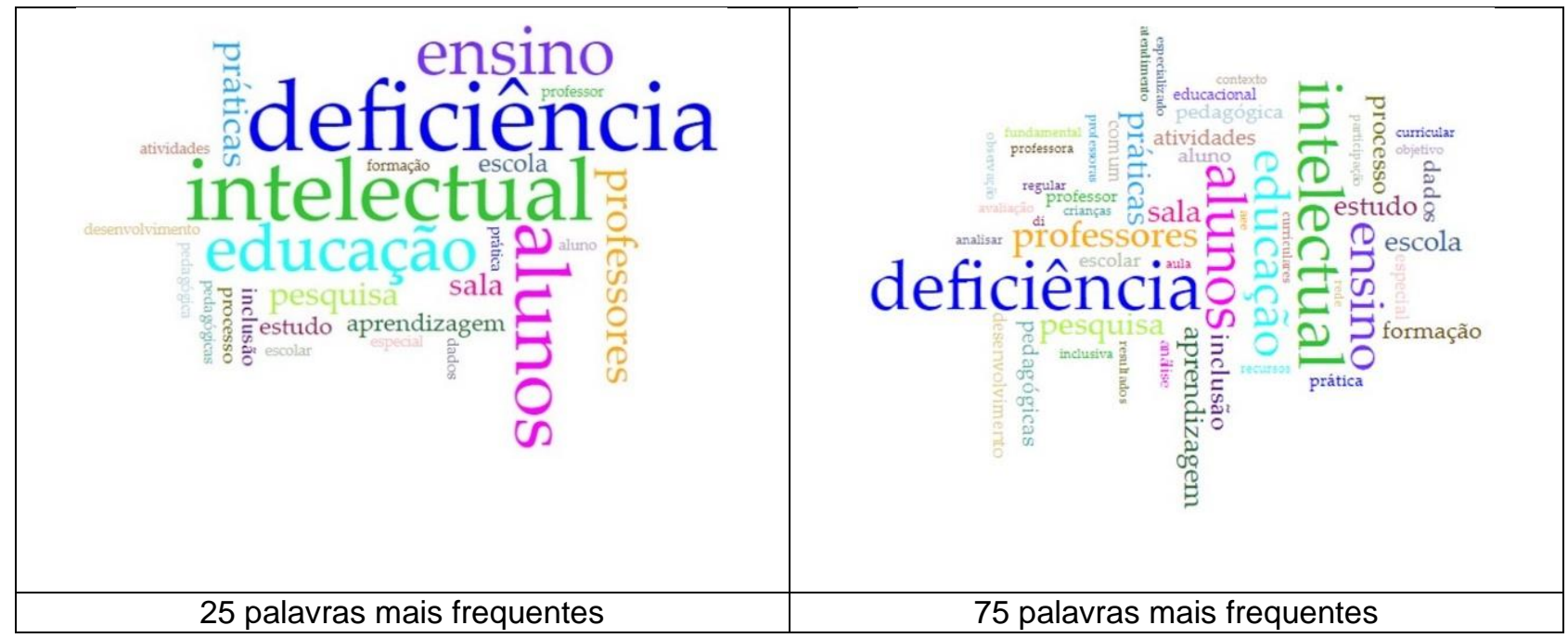

Fonte: Elaboração própria, utilizando a ferramenta Voyant Tools (https://voyant-tools.org/) (2021).

b) Tendência dos termos mais frequentes nos resumos selecionados para análise integral

Figura 2 - Tendência de termos nos resumos selecionados

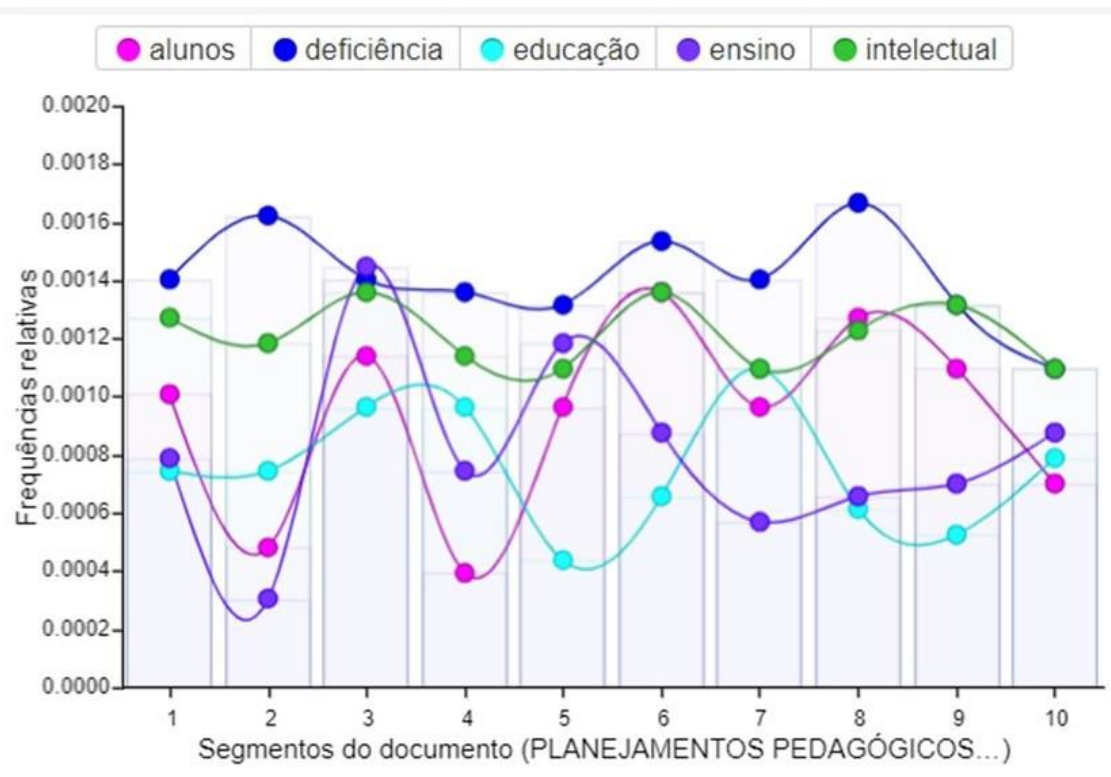

Fonte: Elaboração própria, utilizando a ferramenta Voyant Tools (https://voyant-tools.org/) (2021).

Revista Educação Especial | v. 34 | 2021 - Santa Maria

Disponível em: https://periodicos.ufsm.br/educacaoespecial 
As palavras mais frequentes indicadas na mineração de textos foram: deficiência (322), intelectual (277), alunos (214), ensino (186) e educação (172). Ao serem ampliadas, chamam a atenção, também, as palavras: práticas, escola, processo, aprendizagem e inclusão. Essas palavras indicam coerência em relação ao tema pesquisado e os resultados obtidos com as principais categorias e seus indicadores, a seguir.

3. Indicadores presentes em cada categoria dos textos analisados e implicações para futuros estudos 
http://dx.doi.org/10.5902/1984686X67106

Quadro 1 - Categorias atribuídas e indicadores presentes nos textos analisados na íntegra

(continua)

\begin{tabular}{|c|c|c|c|}
\hline Alguns exemplos de Teses e Dissertações & Categorias & Indicadores presentes nos estudos analisados & $\begin{array}{c}\text { Implicações para futuras } \\
\text { pesquisas }\end{array}$ \\
\hline $\begin{array}{l}\text { 1. Sala de recursos multifuncionais, tecnologia assistiva } \\
\text { e deficiência intelectual: elementos para um novo fazer } \\
\text { pedagógico (Sônia Azevedo de Medeiros) } \\
\text { 2. Adaptações curriculares para alunos com deficiência } \\
\text { intelectual: das concepções às práticas pedagógicas } \\
\text { (Maria Alice de Araújo) } \\
\text { 3.Inclusão escolar de alunos com deficiência intelectual: } \\
\text { prática docente nos anos iniciais do ensino fundamental } \\
\text { público ludovicense (Andréia Carla Pereira) } \\
\text { 4. Deficiência intelectual e mediação docente: } \\
\text { concepções e práticas no atendimento educacional } \\
\text { especializado (AEE) (Laís Venâncio de Melo) } \\
\text { 5.Formação docente a partir de um manual pedagógico } \\
\text { ilustrado para gamificação de atividades como estratégia } \\
\text { na alfabetização inclusiva (Fernanda Beatriz Miranda de } \\
\text { Carvalho) } \\
\text { 6. Atendimento educacional especializado para alunos } \\
\text { com deficiência intelectual na escola regular: } \\
\text { possibilidades de intervenção numa perspectiva } \\
\text { inclusiva (Érika Soares de Oliveira Araújo) } \\
\text { 7. Prática pedagógica aos educandos com deficiência } \\
\text { intelectual numa escola de ensino fundamental com alto } \\
\text { IDEB (Wilma Cardin Silva-Porta) } \\
\text { 8. Alfabetização de alunos com deficiência intelectual: } \\
\text { um estudo sobre estratégias de ensino utilizadas no } \\
\text { ensino regular (Mírian Célia Castellain Guebert) } \\
\text { 9. Sala de recursos multifuncionais, tecnologia assistiva } \\
\text { e deficiência intelectual: elementos para um novo fazer } \\
\text { pedagógico (Sônia Azevedo de Medeiros) } \\
\text { 10. Benefícios e desafios da tutoria por pares para aluno } \\
\text { com deficiência intelectual (Kéren-Hapuque Cabral de } \\
\text { Marins)) }\end{array}$ & $\begin{array}{l}\text { Estratégias } \\
\text { pedagógicas } \\
\text { e recursos } \\
\text { de ensino }\end{array}$ & $\begin{array}{l}\text { Diferenciação de atividades pedagógicas em níveis de complexidade } \\
\text { diferentes, de tal modo que sejam contemplados grupos diferentes. As } \\
\text { atividades em grupo possibilitam isso, com integrantes, também, de } \\
\text { perfis distintos. } \\
\text { Planejamento conjunto entre AEE e sala comum para evitar situações } \\
\text { nas quais os estudantes que possuem diagnóstico de deficiência } \\
\text { intelectual fiquem isolados em sala de aula, com atividades diferentes. } \\
\text { No caso de uso de estratégias de ensino colaborativo, pode ser } \\
\text { interessante e fundamental a presença do professor de AEE em sala } \\
\text { comum. } \\
\text { Proposição de práticas que abordem uma concepção de uso social da } \\
\text { língua enquanto processo de letramento, especificamente em relação } \\
\text { aos estudantes em fase de alfabetização. Isso valorizará distintas } \\
\text { práticas e usos da língua e, portanto, valorizará as diferentes } \\
\text { experiências de vida dos estudantes. }\end{array}$ & $\begin{array}{l}\text { Ampliar a realização de } \\
\text { pesquisas que promovam o } \\
\text { uso de estratégias } \\
\text { colaborativas, tanto das que } \\
\text { abordam esse trabalho entre } \\
\text { professores (AEE e sala } \\
\text { comum), quanto daquelas } \\
\text { que utilizam estratégias } \\
\text { relacionadas aos pares, a } \\
\text { exemplo da tutoria por pares. } \\
\text { Ampliar a realização de } \\
\text { estudos que priorizem fases } \\
\text { específicas do processo de } \\
\text { escolarização de crianças } \\
\text { com deficiência, com foco } \\
\text { para as idades pré-escolar e } \\
\text { dos anos iniciais do Ensino } \\
\text { Fundamental. Nesses } \\
\text { estudos é de extrema } \\
\text { importância que seja dada } \\
\text { atenção especial em relação } \\
\text { aos aspectos de linguagem e } \\
\text { comunicação. }\end{array}$ \\
\hline
\end{tabular}

Revista Educação Especial | v. 34 | 2021 - Santa Maria

Disponível em: https://periodicos.ufsm.br/educacaoespecial 
http://dx.doi.org/10.5902/1984686X67106

Quadro 1 - Categorias atribuídas e indicadores presentes nos textos analisados na íntegra

(continua)

\begin{tabular}{|c|c|c|c|}
\hline Alguns exemplos de Teses e Dissertações & Categorias & Indicadores presentes nos estudos analisados & $\begin{array}{c}\text { Implicações para futuras } \\
\text { pesquisas }\end{array}$ \\
\hline $\begin{array}{l}\text { 1. Mediação pedagógica e deficiência intelectual: em } \\
\text { cena a linguagem escrita (Katia de Moura Graça Paixão } \\
\text { 2. Deficiência intelectual e ensino-aprendizagem: } \\
\text { aproximação entre ensino comum e Salas de Recursos } \\
\text { Multifuncionais (Saulo Fantato Moscardini) } \\
\text { 3. Escolarização de alunos com deficiência intelectual: a } \\
\text { construção de conhecimento e o letramento (Rosiney } \\
\text { Vaz de Melo Almeida) } \\
\text { 4. O processo de alfabetização de uma criança com } \\
\text { deficiência intelectual no } 1^{\circ} \text { ano do ensino fundamental } \\
\text { (Guida Mesquita) }\end{array}$ & $\begin{array}{c}\text { Mediação } \\
\text { pedagógica }\end{array}$ & $\begin{array}{l}\text { Valorização maior da mediação pedagógica em detrimento dos recursos } \\
\text { didático-pedagógicos. Em alguns estudos foi possível notar uma } \\
\text { inversão dessa lógica e alguns pesquisadores chamam a atenção para } \\
\text { isso, reiterando a necessidade de conceber a mediação pedagógica } \\
\text { como ação fundamental para favorecer o processo de aprendizagem } \\
\text { dos estudantes. }\end{array}$ & $\begin{array}{l}\text { Ampliar a realização de } \\
\text { pesquisas que valorizem } \\
\text { uma concepção de prática } \\
\text { pedagógica que destaque a } \\
\text { ação do professor no } \\
\text { processo de ensino- } \\
\text { aprendizagem e que não } \\
\text { seja desarticulada dos } \\
\text { aspectos sociais, culturais da } \\
\text { profissionalização docente. }\end{array}$ \\
\hline $\begin{array}{l}\text { 1. O olhar dos professores sobre adaptação curricular } \\
\text { para alunos com deficiência intelectual: uma ação de } \\
\text { formação continuada na escola (Artur Carmello Neto) } \\
\text { 2. Práticas pedagógicas e inclusão escolar: o processo } \\
\text { de ensino-aprendizagem de alunas com deficiência } \\
\text { intelectual (Mirela Granja Vidal Monteiro) } \\
\text { 3. Educação inclusiva: práticas de professores frente à } \\
\text { deficiência intelectual (Teresa Cristina Coelho dos } \\
\text { Santos). } \\
\text { 4. A prática pedagógica do professor de Atendimento } \\
\text { Educacional Especializado para o aluno com deficiência } \\
\text { intelectual (Adelaide de Sousa Oliveira Neta) } \\
\text { 5. Formação continuada de professores para o } \\
\text { atendimento educacional especializado: desafios e } \\
\text { perspectivas (Edison de Queiroz Junior) } \\
\text { 6. Formação de professores em serviço por meio de } \\
\text { pesquisa colaborativa visando à inclusão de alunos com } \\
\text { deficiência intelectual (Elizabete Humai Toledo) } \\
\text { 7. Avaliação da aprendizagem de alunos com } \\
\text { deficiência intelectual: a experiência de professores do } \\
\text { ensino fundamental em Jijoca de Jericoacoara-CE } \\
\text { (Sheila Maria Muniz) }\end{array}$ & $\begin{array}{l}\text { Políticas } \\
\text { públicas para } \\
\text { melhoria da } \\
\text { escola } \\
\text { regular e da } \\
\text { formação de } \\
\text { professores }\end{array}$ & $\begin{array}{l}\text { Formação inicial e continuada focada em necessidades específicas dos } \\
\text { professores, na elaboração de material educacional e instrucional sobre } \\
\text { as práticas efetivas disponíveis para crianças com deficiência } \\
\text { intelectual. } \\
\text { Investimento e incentivo à qualificação de professores numa perspectiva } \\
\text { inclusiva, com destaque para ações de formação continuada. } \\
\text { Valorização maior da formação específica e de recursos materiais da } \\
\text { escola, assim como uma formação para o uso daqueles existentes. } \\
\text { Investimento em políticas de formação docente com temas sobre } \\
\text { concepções de deficiência e de deficiência intelectual e esclarecimento } \\
\text { aos docentes, por meio dessas formações, de que modo as concepções } \\
\text { e mediações pedagógicas impactam nessa prática e, principalmente, na } \\
\text { constituição dos sujeitos e na construção de um modelo escolar que } \\
\text { considere as diferenças presentes na escola. Muitos estudos apontaram } \\
\text { lacunas atitudinais, pedagógicas e de formação. }\end{array}$ & $\begin{array}{l}\text { Ampliar os estudos sobre } \\
\text { formação docente com } \\
\text { temas sobre concepções de } \\
\text { deficiência e de deficiência } \\
\text { intelectual, indicando de que } \\
\text { modo essas concepções } \\
\text { impactam na ação do } \\
\text { professor no seu dia a dia. }\end{array}$ \\
\hline
\end{tabular}

Revista Educação Especial | v. 34 | 2021 - Santa Maria

Disponível em: https://periodicos.ufsm.br/educacaoespecial 
Quadro 1 - Categorias atribuídas e indicadores presentes nos textos analisados na íntegra

(conclusão)

\begin{tabular}{|c|c|c|c|}
\hline Alguns exemplos de Teses e Dissertações & Categorias & Indicadores presentes nos estudos analisados & $\begin{array}{c}\text { Implicações para futuras } \\
\text { pesquisas }\end{array}$ \\
\hline $\begin{array}{l}\text { 1. Planejamento e práticas curriculares nos processos } \\
\text { de alfabetização de alunos com deficiência intelectual: } \\
\text { experiências e trajetórias em tempos de educação } \\
\text { inclusiva (Géssica Fabiely Fonseca) } \\
\text { 2. Deficiência intelectual e adaptação curricular sob o } \\
\text { olhar de teses e dissertações (Juliessa Ricce Valera) } \\
\text { 3. Uma intervenção colaborativa sobre os processos de } \\
\text { ensino e aprendizagem do aluno com deficiência } \\
\text { intelectual Patrícia. Braun) } \\
\text { 4. Educação Especial e Currículo Escolar: possibilidades } \\
\text { nas práticas pedagógicas cotidianas (Ariadna Pereira } \\
\text { Siqueira Effgen) } \\
\text { 5. O acesso curricular para alunos(as) com deficiência } \\
\text { intelectual na rede regular de ensino: a prática } \\
\text { pedagógica na sala de recursos como eixo para análise } \\
\text { (Hilce Aguiar. Melo) } \\
\text { 6. Adequações curriculares na área da deficiência } \\
\text { intelectual: análise de uma realidade (Wania Aparecida } \\
\text { Boer) } \\
\text { 7. Adequação curricular: um caminho para a inclusão do } \\
\text { aluno com deficiência intelectual (Ester Lopes) } \\
\text { 8. Adaptação curricular em atividades de leitura e escrita } \\
\text { para alunos com deficiência intelectual na perspectiva } \\
\text { colaborativa (Joice Daiane Muiniz) }\end{array}$ & Currículo & $\begin{array}{l}\text { Realização de práticas pedagógicas com a proposição de avaliar os } \\
\text { níveis de desenvolvimento e aprendizagem dos alunos com deficiência } \\
\text { intelectual e estruturar o planejamento educativo, a partir de atividades } \\
\text { pedagógicas individualizadas e diferenciadas com utilização recorrente } \\
\text { de adaptações curriculares direcionadas a este público. } \\
\text { Realização de práticas pedagógicas inovadoras com adaptações } \\
\text { curriculares que valorizem a mediação do conhecimento e a } \\
\text { colaboração entre os professores do AEE e da sala comum. Em } \\
\text { muitos estudos foi observado que essas adaptações continuam sendo } \\
\text { organizadas e desenvolvidas na maior parte do tempo, apenas pelos } \\
\text { professores do AEE. }\end{array}$ & $\begin{array}{l}\text { Ampliar a realização de } \\
\text { pesquisas que indiquem } \\
\text { possiblidades de } \\
\text { implementação de } \\
\text { estratégias colaborativas na } \\
\text { sala comum. }\end{array}$ \\
\hline
\end{tabular}

Fonte: Elaboração própria (2021).

Revista Educação Especial | v. 34 | 2021 - Santa Maria

Disponível em: https://periodicos.ufsm.br/educacaoespecial 
http://dx.doi.org/10.5902/1984686X67106

\section{Discussão}

De modo geral, observou-se uma predominância de estudos descritivos que buscam identificar concepções de professores sobre a deficiência intelectual, caracterizar as práticas pedagógicas desenvolvidas com esses estudantes e, em menor expressão, há também estudos que analisam essas práticas do ponto vista documental, seja considerando as políticas existentes no âmbito nacional voltadas especificamente para esse público, seja em relação aos documentos da escola, principalmente, o planejamento docente.

Ainda, considerando esses aspectos gerais, os procedimentos metodológicos adotados em relação às pesquisas desenvolvidas indicam uma predominância da abordagem qualitativa, coerentemente, com as áreas envolvidas: Educação e Ensino. E os instrumentos adotados de maneira predominante nas coletas de dados foram: análise documental, observação, entrevistas e questionários. Em algumas pesquisas, também foi possível observar intervenções educacionais a partir do uso de planejamentos curriculares, com perspectiva colaborativa entre a sala comum e o serviço de Atendimento Educacional Especializado (AEE) desenvolvido na escola.

Feitas tais considerações, passaremos agora a destacar as discussões principais presentes nos textos analisados, com atenção para os aspectos que mais chamaram a atenção em relação às quatro categorias estabelecidas, a saber: Estratégias pedagógicas e recursos de ensino; Mediação pedagógica; Políticas públicas para melhoria da escola regular e da formação de professores; e Currículo.

As duas primeiras categorias estão diretamente ligadas às práticas pedagógicas, e referiram-se à concepção e execução dessas práticas ou de planejamentos pedagógicos presente nos estudos. Em relação à concepção, nos estudos analisados foi possível notar múltiplas dimensões do trabalho e da formação docente. Esse aspecto chamou ainda mais a atenção quando não foi possível separar os trabalhos por meio dos descritores, de modo a conduzir uma discussão mais didática em relação à organização da seção de discussão do nosso artigo. Até a etapa de mineração de textos isso foi possível, porém, ao começar a ler os trabalhos, por mais que alguns deles contivessem em seu título e em seu objetivo aspectos mais voltados à prática de ensino, não seria possível considerá-los sem nos remeter, por exemplo, à formação de professores ou aos aspectos do currículo. 
Consideramos este um ponto positivo e que indica que as pesquisas têm observado a importância dessa articulação.

Por outro lado, no campo da Educação Especial, as discussões mais específicas voltadas para a Didática ainda são tímidas, talvez pelas próprias características da constituição desse campo (CASAGRANDE, MAINARDES, 2021). Uma observação do contrário também é válida, ou seja, não são encontradas discussões específicas sobre inclusão escolar na área da Didática. É importante reiterar que ora a Didática se vincula aos aspectos curriculares, ora aos aspectos de estratégias de ensino. Para Roldão (2009), o conhecimento didático diz respeito ao núcleo da ação de ensinar, intencionalidade pedagógica estratégica de gerar e avaliar aprendizagens pretendidas. Essa preocupação central, portanto, deve sim incluir estratégias que busquem a participação de todos os estudantes em sala de aula, tenham estes ou não deficiência.

Em relação à execução dessas práticas foi possível observar que os trabalhos que ocorrem em colaboração (AEE e sala comum) ainda são muito tímidos. Sabemos que prática pedagógica não pode ser considerada de modo isolado como transmissão de conhecimento ou como estratégia em si, pois ela deve ser analisada em toda a sua complexidade dos atores envolvidos e seus contextos social, político e econômico (CARDOSO et al., 2012). Por isso, reforçamos que a colaboração deve predominar entre esses atores numa escola pretensamente inclusiva.

A terceira categoria, que trata de questões relacionadas à melhoria da escola regular e da formação de professores, também chamou muito a atenção, principalmente, porque alguns resultados de pesquisas permanecem como denúncias em relação à falta de planejamentos estratégicos para a formação continuada ou em serviço e a falta de sensibilidade em relação às especificidades das crianças com diagnóstico de deficiência intelectual. Isso revela também um problema em relação à acessibilidade atitudinal e uma ausência de conhecimento sobre as condições específicas de desenvolvimento dessas crianças. E isso reforça e indica, diretamente, um importante elemento que é necessário melhorar, para que essas crianças permaneçam na escola e tenham garantido o seu direito de aprender.

Essa falta de sensibilidade às diferenças no processo de desenvolvimento e de aprendizagem demonstra que ainda há muito a ser construído para um processo de inclusão escolar que certifique a desconstrução de estigmas relacionados às deficiências, 
em favor de um atendimento específico às necessidades de vários sujeitos, tenham eles ou não algum tipo de deficiência.

Esses dados só reforçam o quanto professores demandam, não somente uma formação inicial voltada para uma perspectiva inclusiva, mas também recursos e capacitação para mediar os processos de aprendizagem com o objetivo de corresponder ao atendimento educacional individualizado, quando este for necessário. Vários estudos (ONEESP, 2011, 2014) indicam que as barreiras atitudinais são tão problemáticas quanto à especialização profissional para uma atuação que considere as diferenças presentes na escola durante a efetivação de práticas pedagógicas que promovam autonomia nos processos de desenvolvimento e aprendizagem. Por isso, é necessário que a discussão sobre o currículo dos cursos de Pedagogia, formação continuada e o fortalecimento de ações de inclusão escolar sejam mais frequentes dentro dos ambientes acadêmicos. Destacamos o curso de Pedagogia, porque o foco de nosso texto é o Ciclo I do Ensino Fundamental, mas com certeza, essa discussão abrange também outros cursos e as demais licenciaturas.

Outro aspecto observado nos estudos que reforça essa discussão e as dimensões envolvidas na prática pedagógica, foi a necessidade de formação dos professores, tanto inicial, quanto continuada. Praticamente todos os estudos reforçam isso, principalmente, quando reiteram a importância de um trabalho colaborativo entre professores ou profissionais de apoio e o professor da sala comum. Nesse contexto, não podemos perder de vista, a importância dessas formações para o desenvolvimento profissional, mas também, considerando, fundamentalmente as questões relacionadas à profissionalidade (SACRISTÁN, 1985), pois há conteúdos específicos para cada etapa de escolarização. Um exemplo simples dessa diferença está entre as formações de licenciaturas, de modo geral, e a formação em Pedagogia. Não tem como não admitir a diferença de um profissional que atua nos anos iniciais do Ensino Fundamental e outro que atua no Ensino Médio, por exemplo.

Os dados presentes na quarta e última categoria (Currículo) reforçam as discussões sobre o planejamento colaborativo e trazem à tona outro aspecto importante ainda tímido nas produções científicas e nas políticas públicas relacionadas à inclusão escolar: o Planejamento Educacional Especializado (PEI). Sem dúvida, esse planejamento seria uma excelente oportunidade para se trabalhar o currículo, uma das mais importantes dimensões 
da prática pedagógica, especialmente, no caso da existência de necessidades de adaptações curriculares, frequentemente observadas para alguns casos de deficiência intelectual (GLAT, PLETSCH, 2013). O PEI favorece uma nova dinâmica no processo de ensino-aprendizagem, podendo ser utilizado como uma estratégia para promover o desenvolvimento e a futura inserção social de alunos com deficiência (PLETSCH, 2009) e por isso também é considerado um relevante instrumento que possibilita redimensionar as práticas pedagógicas (CAMPOS; PLETSCH, 2014).

Em alguns lugares, o PEl já faz parte da legislação local, a exemplo do Estado de Minas Gerais, por meio da Resolução 4256/2020 (MINAS GERAIS, 2020). Nessa Resolução ele é mencionado como Plano de Desenvolvimento Individual (PDI) que se trata de um instrumento semelhante ou com o mesmo propósito. E, muito embora ele ainda não seja um instrumento garantido em legislação nacional, as pesquisas realizadas com essa ferramenta indicam, cada vez mais, que ela é fundamental, tanto para garantir o planejamento conjunto (professores e profissionais de apoio), quanto a participação da criança em todas as atividades, especialmente, naquelas desenvolvidas na sala comum.

Sobre o trabalho colaborativo, essa seria uma oportunidade para colocá-lo em prática. Muitas pesquisas, ao longo de décadas, têm indicado, cada vez mais que ele é o caminho mais promissor em relação à atuação com perspectiva inclusiva. A formação com foco para o trabalho colaborativo pode auxiliar os professores no cotidiano escolar, durante as diferentes situações vivenciadas. Para Santos, Makishima e Silva (2015), ele consiste em uma estratégia pedagógica em que o professor especialista na área de Educação Especial e os professores da sala comum planejam de forma articulada, procedimentos de ensino para atendimento às necessidades educacionais especiais desse público. E, portanto, pode promover o desenvolvimento de práticas pedagógicas e favorecer a parceria de trabalho entre profissionais do AEE e da sala comum, desencadeando estratégias e a preparação do plano de ação e intervenção da escola (SANTOS; MAKISHIMA; SILVA, 2015).

Nesse contexto, não podemos esquecer que a gestão escolar, ao se implicar como parte primordial do planejamento escolar, precisa realizar um trabalho coletivo junto aos professores para apoiar essas práticas pedagógicas e estabelecer um foco de gestão considerando a perspectiva inclusiva, para eliminar qualquer possibilidade de exclusão da criança nesse contexto (DUTRA, GRIBOSKI, 2005). 
http://dx.doi.org/10.5902/1984686X67106

Por fim, embora não façam parte dessas categorias específicas, não podemos deixar de mencionar alguns estudos que reforçam a importância de serem considerados elementos que respeitam características específicas presentes no diagnóstico de deficiência intelectual e que podem favorecer o engajamento e o processo de aprendizagem desses sujeitos e mais especificamente o processo de alfabetização (GUEBERT, 2013).

Citamos como exemplo as estratégias que reforçam o uso de suportes visuais (ZABOROSKI-OLEINIK, 2020). Os suportes visuais são mencionados na literatura como estímulos pictográficos e gráficos que aumentam a compreensão e o aprendizado em sujeitos que, de outra forma, podem ter dificuldades de comunicação (RUTHERFORD et al, 2020). Esses suportes são comuns em intervenções com crianças autistas e crianças com deficiência intelectual e podem destacar um significado particular, indicar ao sujeito e seu parceiro de comunicação significados compartilhados e respostas esperadas em uma determinada situação (OLIVEIRA, 2019). Sem dúvida, esses suportes também desempenham um papel fundamental na melhoria do engajamento em atividades de comunicação e interação de pessoas com Transtorno do Espectro Autista (OLIVEIRA, 2021) que podem ter uma deficiência intelectual associada.

As categorias destacadas advindas das pesquisas analisadas reforçam, mais uma vez, a prática pedagógica como intersecção dinâmica de saberes, sendo influenciada também pela organização escolar, pela cultura individual do docente e a cultura do grupo de estudantes. Reiteramos que o trabalho colaborativo tem se mostrado como uma prática que, associada às formações continuadas e a aplicabilidade das legislações vigentes, pode proporcionar importantes ações com vistas à inclusão escolar.

\section{Considerações finais}

Este artigo propôs uma revisão de literatura com o objetivo de mapear as produções científicas que pudessem auxiliar nos planejamentos pedagógicos com perspectiva colaborativa. Consideramos que esse objetivo foi alcançado, tendo em vista que encontramos pesquisas que apresentam elementos fundamentais para essa prática pedagógica.

Os resultados permitiram concluir e reforçar que a concepção de prática pedagógica envolve múltiplas dimensões do trabalho docente. Essa noção está muito presente nos 
estudos, já que estes não focaram apenas um aspecto dessa prática. Isso permite reiterar que a prática pedagógica não pode ser considerada de modo isolado como transmissão do conhecimento, mas sim do ponto de vista da complexidade dos atores envolvidos e de seus contextos social, político e cultural. Por outro lado, reiteramos que o discurso de preparação da escola e de professores para receber as crianças com deficiência, como se fosse possível construir um manual, com receitas e passo a passo, com base em suposições já está saturado e não se sustenta mais, tendo em vista, principalmente, o direito de acesso à Educação que todos possuem.

Os resultados também permitiram concluir que as discussões sobre acessibilidade atitudinal, concepções sobre deficiência intelectual, adaptações curriculares, expectativas docentes sobre o processo de aprendizagem desses estudantes e formação de professores permanecem em cena e, portanto, ainda precisamos avançar nessas discussões em futuras pesquisas.

Por fim, as pesquisas reforçam a importância de se considerar aspectos que respeitam características específicas presentes no diagnóstico de deficiência intelectual e que podem favorecer o engajamento e o processo de aprendizagem desses sujeitos nas práticas pedagógicas, assim como em outras atividades. Para tanto, é necessário também uma atenção maior em relação aos processos de mediação pedagógica, tema pouco explorado nos trabalhos analisados e, por isso, bastante importante para futuros estudos.

Um dos pontos fundamentais relacionados a essa mediação é a necessidade de rever concepções sobre a deficiência intelectual e dos aspectos que envolvem a atuação pedagógica com perspectiva inclusiva: elementos amplamente discutidos na literatura especializada, ao longo dos estudos nos contextos da Educação Especial e da Educação Inclusiva (MUGNAI; 2017; ALMENDROS; LARDOEYT, 2012; PAGNI, 2015).

Enfim, a nossa análise demonstrou que é necessário continuar a exploração dessa temática, para que fiquem mais claras as relações da Didática presentes na Educação Especial, pois a limitação dos termos pode deixar de fora estudos de outras áreas, tais como os de políticas públicas e política educacional, por exemplo, fundamentais para a discussão da formação de professores. Ademais, parece ser necessário incluir nessa discussão indicadores do cotidiano, para que a compreensão das práticas de ensino voltadas aos sujeitos com deficiência intelectual seja ampliada. 


\section{Referências}

ALLES, Elisiane Perufo; CASTRO, Sabrina Fernandes de; MENEZES, Eliana da Costa Pereira; DICKEL, Cláudia Adriane Graeff. (Re)Significações no Processo de Avaliação do Sujeito Jovem e Adulto com Deficiência Intelectual. Revista Brasileira de Educação Especial [online]. 2019, v. 25, n. 3. Acesso em: 04 out. 2021. Disponível em: https://doi.org/10.1590/s1413-65382519000300002.

ALMEIDA, Patrícia Cristina Albieri de.; BIAJONE, Jefferson. Saberes docentes e formação inicial de professores: implicações e desafios para as propostas de formação.

Educação e Pesquisa, [online], v. 33, n. 2, p. 281-295. Acesso em: 02 nov. 2021. Disponível em:

https://www.scielo.br/j/ep/a/8gDXyFChcHMd5p6drYRgQSn/?format=pdf\&lang=pt

ALMENDROS, Inácio Calderón; LARDOEYT, Sabina Habegger. Educación, Hándicap e Inclusión - Una lucha familiar contra una escuela excluyente, Granada: Máqina edicones, 2012, $176 \mathrm{p}$.

APA. Associação Americana de Psiquiatria. DSM-5: Manual Diagnóstico e Estatístico de Transtornos Mentais. 5aㅡ ed. Porto Alegre: Artmed, 2014. 992p.

BARDIN, Laurence. Análise de conteúdo. Tradução: RETO, Luiz Antero; PINHEIRO. Augusto. São Paulo: Edições 70, 2011.

BRASIL. Secretaria da Educação do Estado de São Paulo/Ministério da Educação. Política Nacional de Educação Especial na Perspectiva da Educação Inclusiva. Brasília, DF, 2008.

CAMPOS, Erica Costa Vilese; PLETSCH, Márcia Denize. Escolarização do aluno com deficiência intelectual: dialogando com o currículo e o plano educacional individualizado. In: VI Congresso Brasileiro de Educação Especial e IX Encontro Nacional dos Pesquisadores da Educação Especial. UFSCAR/ABPEE, São Carlos, 2014.

CAPELLINI, Vera Lúcia Messias Fialho; ZERBATO, Ana Paula. O que é Ensino Colaborativo? São Paulo: Edicon, 2019.

CARDOSO, Aliana Anghinoni; DEL PINO, Mauro Augusto Burkert; DORNELES, Caroline Lacerda. Os saberes profissionais dos professores na perspectiva de Tardif e Gauhier: contribuições para o campo de pesquisa sobre os saberes docentes no brasil, Seminário de Pesquisa em educação Região Sul, 2012.

CASAGRANDE, Rosana Castro; MAINARDES, Jefferson. O campo acadêmico da Educação Especial no Brasil. Revista Brasileira de Educação Especial, [online], v. 27, p. 119-138. Acesso em: 02 ago. 2021. Disponível em: https://doi.org/10.1590/1980$54702021 \mathrm{v} 27 \mathrm{e} 0132$ 
COSTA, Angelo Brandelli; ZOLTOWSKI, Aana Paula Couto; KOLLER, Silvia Helena; TEIXEIRA, Marco Antonio. Construção de uma escala para avaliar a qualidade metodológica de revisões sistemáticas. Ciência \& Saúde Coletiva, v. 20, n. 8, p. 2441 2452, 2015. Acesso em: 02 set. 2020. Disponível em: http://www.scielo.br/pdf/csc/v20n8/1413-8123-csc-20-08-2441.pdf.

DUTRA, Claudia Pereira; GRIBOSKI, Claudia Maffini. Gestão para inclusão. Revista Educação Especial, Santa Maria, 26, 2005. Acesso em: 02 ago. 2021. Disponível em: https://periodicos.ufsm.br/educacaoespecial/article/view/4372/2566.

FRANCO, Maria Amélia. Prática pedagógica e docência: um olhar a partir da epistemologia do conceito. Revista Brasileira de Estudos Pedagógicos, Brasília, v. 97, n. 247, p. 534-551, 2016. Acesso em: 01 fev. 2021. Disponível em: https://doi.org/10.1590/s2176-6681/288236353.

GLAT, Rosana; PLETSCH, Márcia Denize. (Orgs.). Estratégias educacionais diferenciadas para alunos com necessidades especiais. Rio de Janeiro: EdUERJ, 2013.

GHIRELLO-PIRES, Carla Salati. Formas usuais de entendimento sobre a síndrome de Down e a teoria histórico-cultural. In: BARROCO, S. M. S.; LEONARDO, N. S.; SILVA, T. do S. (Orgs.). Educação especial e Teoria Histórico-Cultural: em defesa da humanização do homem. Maringá: Eduem, 2012, p. 167-192.

GUEBERT, Mírian Célia Castellain. Alfabetização de alunos com deficiência intelectual: um estudo sobre estratégias de ensino utilizadas no ensino regular. 2013. 119 f. Tese (Doutorado em Educação: Historia, Política, Sociedade) - Pontifícia Universidade Católica de São Paulo, Programa de Estudos Pós-graduação em Educação: Historia, Política, Sociedade, 2013.

JANUZZI, Gilberta. A educação do deficiente no Brasil: dos primórdios ao início do século XXI. 2. ed. Campinas: Autores, SP, 2006.

LUCKASSON, Ruth.; BORTHWICK-DUFFY, Sharon.; BUNTINX, Wil H.; COULTER, David. et al. Mental retardation: Definition, classification, and systems of support, 10th Ed., Washington, DC: American Association on Mental Retardation, 2002.

LUTOSA, Francisca; MELO, Claudiana Maria. Organização e princípios didáticos para gestação da sala de aula inclusiva: a gênese de práticas pedagógicas de atenção à diversidade. In: FRANCO, Marco Antonio Melo; GUERRA, Lenor Bezerra. Práticas Pedagógicas de inclusão: situações de sala de aula - vol. 3, 1 ed., Jundiaí, SP, 2018.

MEDRADO, Cylene; GOMES, Vívian Martins; NUNES SOBRINHO, Francisco de Paula. Atributos Teórico-Metodológicos da Revisão Sistemática das Pesquisas Empíricas em Educação Especial: Evidências Científicas na Tomada de Decisão sobre as Melhores Práticas Inclusivas. In: NUNES, L. R. d'O de P. (Org.), Novas trilhas no modo de fazer pesquisa em Educação Especial (pp. 105-126). Marília: Marquezine \& Manzini/ABPEE, 2014. 
MINAS GERAIS. Resolução SEE no 4256/2020. Normatização e organização da Educação Especial na rede estadual de Ensino de Minas Gerais. Secretaria do Estado de Educação, Belo Horizonte, 2020.

MUGNAI, Camila. Mudança de atitudes sociais de professores em relação à inclusão: transformação junto com alunos. Revista Educação Especial, v. 30, n. 59, p. 723-736, 2017. Acesso em: 10 nov. 2017. Disponível em:https://periodicos.ufsm.br/educacaoespecial/article/view/28429/pdf_1.

OLIVEIRA, Emely Kelly. S. S. Engajamento de Crianças com Transtorno do Espectro Autista em Atividades de um Programa Metatextual de Produção de Histórias. [Dissertação de Mestrado]. Programa de Pós-graduação em Educação. Universidade Estadual Paulista, Faculdade de Filosofia e Ciências, Marília, 2021.

OLIVEIRA, Jaima Pinheiro de. Proposta de Análise de Funções Comunicativas em Crianças com Deficiência (PAFCCD). IN: OLIVEIRA, Jáima Pinheiro de.; MATA, Simara pereira da.; BLANCO, Marília Bazan. Educação Infantil, Linguagem e Inclusão Escolar. São Carlos: De Castro Editora, 2021.

OLIVEIRA, Jaima Pinheiro de. Novo PRONARRAR. Suporte estruturado para a emergência e o Desenvolvimento de Histórias Infantis. Curitiba: ed. CRV, 2019.

ONEESP. Observatório Nacional de Educação Especial. Publicações. Relatórios (1 a 4 - 2011 a 2014). Disponível em: https://www.oneesp.ufscar.br/publicacoes. Acesso em: 20 mai 2021.

PAGNI, Pedro. Encontros com a deficiência: de ensaios da ficção a testemunhos sobre a sua ética em uma rede (in) visível. Revista Diálogos e Perspectivas em Educação Especial. [online]. v. 2, n. 1, 2015, p. 103-120. Acesso em: 02 mar. 2021. Disponível em: http://revistas.marilia.unesp.br/index.php/dialogoseperspectivas/article/view/5295/3708.

PATTO, Maria Helena. A produção do fracasso escolar: histórias de submissão e rebeldia (4를 ed). São Paulo: Casa do Psicólogo, 2015.

PLETSCH. Márica Denize. A formação de professores para a educação inclusiva: legislação, diretrizes políticas e resultados de pesquisa. In: Educar em Revista, v. 33, p. 143-156, Paraná, 2009.

ROLDÃO, Maria do Céu. Estratégias de Ensino: o saber e o agir do professor. Vila Nova de Gaia: Fundação Manuel Leão, 2009.

RUTHERFORD Marrion; BAXTER, Julie; GRAYSON, Zoe; JOHNSTON, Lorna; O'HARE, Anne. Visual supports at home and in the community for individuals with autism spectrum disorders: A scoping review. Autism. 24, 2, p. 447-469, 2020. Acesso em: 24 jan. 2021. Disponível em: doi:10.1177/1362361319871756

SACRISTÁN, José Gimeno. Consciência e ação sobre a prática como libertação profissional dos professores. In: NÓVOA, António. Profissão professor. 2. ed. Porto: Porto, 1995. p. 63-92. 
SANTOS, Shirley Aparecida dos; MAKISHIMA, Edne Aparecida Claser; SILVA, Thaís Gama da. O Trabalho Colaborativo entre o professor especialista e o professor das disciplinas - o fortalecimento das Políticas Públicas para Educação Especial no Paraná. In: XII Congresso Nacional de Educação: Formação de professores, complexidade e trabalho docente. EDUCERE, p. 8312-8325, 2015.

SCHALOCK, Robert L.; BORTHWICK-DUFFY, Sharon A.; BRADLEY, Valerie J.; BUNTINX, Wil H. et al. Mental retardation: Definition, classification, and systems of support, 11th Ed., Intellectual disability: Definition, classification, and systems of support (11th Ed.). Washington, DC: American Association on Intellectual and Developmental Disabilities, 2010.

SEBASTIÁN-HEREDERO, Eladio. Diretrizes para o Desenho Universal para a Aprendizagem (DUA). Revista Brasileira de Educação Especial, v. 26, n. 4, 2020. Acesso em: 02 nov. 2021. Disponível em: https://doi.org/10.1590/198054702020v26e0155

SHULMAN, Lee S. Those who understand: knowledge growth in teaching. Educational, v. 15, n. 2, p. tional 4-14, 1986.

TARDIF, Maurice. Saberes docentes e formação profissional. 17ª ed. Petrópolis, RJ: Vozes, 2014.

VAZ, Daniela Virgínia; ANTUNES, Ana Amélia Moraes; FURTADO, Sheyla Rossana Cavalcanti. Tensões e possibilidades no campo da reabilitação sob a ótica dos estudos da deficiência. Cadernos Brasileiros de Terapia Ocupacional, 27(4), 917-928, 2019.

ZABALA, Antoni. A prática educativa: como ensinar. Porto Alegre: Editora Artes Médicas Sul Ltda., 1998.

ZABOROSKI-OLEINIK, Ana Paula. Construção e avaliação do impacto de um programa de ensino metatextual para desenvolver a narrativa escrita de estudantes com deficiência intelectual. Tese (Doutorado em Educação) - Universidade Estadual Paulista "Júlio de Mesquita Filho" (UNESP), Faculdade de Filosofia e Ciências, Marília, 2020.

\section{Notas}

${ }^{1}$ A partir deste ano, a AAIDD passou a considerar 21 anos de idade. 